\title{
Correction to: Effectiveness and cost- effectiveness of treatment with additional enrollment to a homeopathic integrated care contract in Germany
}

\author{
Benjamin Kass", Katja Icke, Claudia M. Witt and Thomas Reinhold
}

\section{Correction to: BMC Health Serv Res 20, 872 (2020) https://doi.org/10.1186/s12913-020-05706-4}

Following publication of the original article [1], the authors would like to remove the incorrect group difference for atopic dermatitis in the Abstract. The correct group difference of $\Delta$-DLQI: $-1.4, p=0.086$ is neither clinically relevant nor statistically significant. The correct value is stated in the main text and discussed in the correct way.

The sentence currently reads:

The primary effectiveness outcomes after six months were statistically significant in favor of the HOM group for migraine or headache ( $\Delta=$ difference between groups, days with headache: $-0.9, p=0.042)$, asthma $(\Delta-\mathrm{AQLQ}(\mathrm{S}):+0.4, p=$ $0.014)$, atopic dermatitis $(\Delta$ - DLQI: $-5.6, p \leq 0.001)$ and depression ( $\Delta$-BDI-II: $-5.6, p \leq 0.001)$.

The sentence should read:

The primary effectiveness outcomes after six months were statistically significant in favor of the HOM group for migraine or headache $(\Delta=$ difference between groups, days with headache: $-0.9, p=0.042$ ), asthma $(\triangle$-AQLQ $(\mathrm{S}):+0.4, p=0.014)$ and depression $(\Delta$-BDI-II: $-5.6, p \leq 0.001)$.
Published online: 30 September 2020

\section{Reference}

1. Kass B, et al. Effectiveness and cost-effectiveness of treatment with additional enrollment to a homeopathic integrated care contract in Germany. BMC Health Serv Res. 2020;20:872. https://doi.org/10.1186/s12913020-05706-4.

The original article can be found online at https://doi.org/10.1186/s12913020-05706-4

* Correspondence: benjamin.kass@charite.de

Institute for Social Medicine, Epidemiology and Health Economics, Charité Universitätsmedizin Berlin, corporate member of Freie Universität Berlin,

Humboldt-Universität zu Berlin, and Berlin Institute of Health, Berlin, Germany

(c) The Author(s). 2020 Open Access This article is licensed under a Creative Commons Attribution 4.0 International License, which permits use, sharing, adaptation, distribution and reproduction in any medium or format, as long as you give appropriate credit to the original author(s) and the source, provide a link to the Creative Commons licence, and indicate if changes were made. The images or other third party material in this article are included in the article's Creative Commons licence, unless indicated otherwise in a credit line to the material. If material is not included in the article's Creative Commons licence and your intended use is not permitted by statutory regulation or exceeds the permitted use, you will need to obtain permission directly from the copyright holder. To view a copy of this licence, visit http://creativecommons.org/licenses/by/4.0/ The Creative Commons Public Domain Dedication waiver (http://creativecommons.org/publicdomain/zero/1.0/) applies to the data made available in this article, unless otherwise stated in a credit line to the data. 